\title{
UNIVERSUM

\section{EL ÁLBUM DEL SANTA LUCÍA COMO ARTEFACTO NARRATIVO VISUAL. BENJAMÍN VICUÑA MACKENNA Y EL REGISTRO FOTOGRÁFICO}

\section{El Álbum del Santa Lucía as a visual narrative artifact. Benjamín Vicuna Mackenna and the photographic registers}

\author{
Cecilia Rodríguez Lehmann ${ }^{\prime}$ (iD \\ ${ }^{1}$ Universidad Austral de Chile, Chile.

\section{RESUMEN}

Este artículo estudia el Álbum del Santa Lucía (1874) de Benjamín Vicuña Mackenna como un artefacto cultural cuya construcción narrativo-visual revela formas modernas de entender lo fotográfico y lo escritural. Más allá de la noción del álbum como registro de las transformaciones urbanísticas emprendidas por el Intendente de Santiago, se muestra aquí el funcionamiento de esta pieza como una obra en sí misma, con una riqueza conceptual que no ha sido suficientemente estudiada. La manera cómo Vicuña Mackenna pone a interactuar fragmentos escritos y fotográficos en un solo relato devela novedosas formas de articular sentidos. Del mismo modo, las reflexiones en torno a lo fotográfico, lo visual y los aparatos ópticos que introduce Vicuña Mackenna nos permiten ver cómo estos registros se van entremezclando en la cultura finisecular chilena. PALABRAS CLAVE: Benjamín Vicuña Mackenna; álbum; fotografía; visualidad; narración.

\section{ABSTRACT}

Benjamín Vicuña Mackenna's Album de Santa Lucía ( 1874 ) is studied here as a cultural artifact whose visual narrative construction reveals modern ways to understand the relationship between photography and writing. Beyond the notion of the album as a testimony of the urban transformations undertaken by the Intendent of Santiago, this article delves into the complexity of a piece gifted with a not sufficiently studied conceptual richness. Vicuna Mackenna elaborates a single narration by means of a noteworthy combination of written and photographic fragments, thus revealing novel ways to articulate senses. Moreover, Vicuña Mackenna's reflections on photographic, visual, and optical devices show how these registers were intermingled in the Chilean fin de siècle culture, as well as the way this author was acquainted with the global debates that were then taking place on these matters.

KEYWORDS: Benjamín Vicuña Mackenna; album; photography; visuality; narrative.

Fecha de Recepción 2O2O-O3-IO
Fecha de Evaluación

2020-08-2I
Fecha de Aceptación

$2020-10-22$ 


\section{INTRODUCCIÓN}

Entre el año I872 y 1874 se llevaron a cabo en la ciudad de Santiago de Chile grandes remodelaciones que convertirían al Cerro Santa Lucía en un paseo "moderno". A semejanza de los parques de Europa, se intentaba construir un lugar para el esparcimiento y el disfrute de los citadinos. Jardines, fuentes, esculturas, terrazas, museos, todo confluía para otorgarle al nuevo espacio urbano un aire de modernidad irrefutable. Benjamín Vicuña Mackenna, Intendente de la ciudad de Santiago para ese momento, vio en el vistoso e ineludible peñasco, la posibilidad de construir una magnífica escena moderna que podría ser contemplada desde distintos puntos de la ciudad. Su carácter elevado era idóneo para constituirse en el gran emblema de una nueva urbe que se abría paso a fuerza de voluntad, diseño, ingeniería, buen gusto, etc.

Todo este proceso de transformación del peñón en parque urbano tuvo un correlato visual: el Álbum del Santa Lucía (I874). Se trataba de un álbum escrito y diseñado por el propio Vicuña Mackenna en donde se describían las principales bondades del parque, así como su proceso de construcción, los costos, la manera de recorrerlo, los lugares a visitar, etc. En una lujosa encuadernación, el álbum combinaba textos y fotografías como una manera de divulgar los adelantos del parque más allá de sus posibles visitantes.

Este álbum fotográfico ha sido estudiado desde unas perspectivas que han privilegiado su carácter referencial; el álbum como un registro de las transformaciones por las que atravesó la ciudad de Santiago. Dentro de estas perspectivas, se encuentran los trabajos que se han centrado en las modificaciones arquitectónicas (Pérez de Arce, Astaburruaga y Rodríguez 1993; Hidalgo 2009), e igualmente aquellos que leyeron en el álbum la modificación del valor iconográfico y cultural del cerro (Peliowsky 20ı6; Peliowsky y Valdés 20ı8; Chávez 20I2). En algunos de estos estudios se ha tocado el valor de lo fotográfico y los cambios que se producen en la mirada, especialmente en la mirada panorámica que el cerro ofrecía de la ciudad, pero se ha obliterado de alguna manera el propio álbum como una construcción narrativa visual en sí misma, como un aparato óptico.

Me gustaría centrarme aquí en el Álbum del Santa Lucía como objeto de estudio y en las formas cómo se articularon en él una serie de narrativas visuales-escriturales que sobrepasan la idea de registro y se insertan en discusiones modernas sobre lo fotográfico, lo artístico, lo impreso, etc. Más allá del registro, Vicuña Mackenna hizo otro tipo de construcción, la de un relato fotográfico/verbal complejo con varios niveles de significación y con disertaciones muy importantes sobre la fotografía, los aparatos ópticos, lo visual, entre otros. 


\section{EL ÁLBUM FOTOGRÁFICO IMPRESO}

Partamos de las formas. Si bien Vicuña Mackenna en algunos momentos habla de esta obra como libro, la forma específica que ha escogido es la del álbum. La idea del álbum ya nos coloca en un horizonte conceptual complejo. Bajo la categoría del álbum el siglo XIX denomina objetos muy diversos: álbum es, por ejemplo, el cuaderno vacío que llenan las señoritas en su casa con autógrafos, poemas, fotografías; álbum es el libro con orificios que sirve para ordenar y guardar las fotografías familiares; álbum es el cuaderno con que los exploradores llevan sus anotaciones; álbum es el nombre de innumerables periódicos y revistas de la época; álbum es también como se denominan algunos materiales impresos difíciles de clasificar que incluyen a veces solo ilustraciones y en otros ilustraciones y textos.

Ante esta diversidad podríamos intentar un esbozo de orden a través de dos grandes categorías: el álbum como cuaderno vacío que debe ser llenado y el álbum como una publicación con ilustraciones $-\mathrm{y}$ a veces texto- ya impresos. Dentro de este último encontraremos diversos tipos de ilustraciones, principalmente grabados, litografías y fotografías; imágenes que pueden ser reproducidas con una relativa facilidad y que hablan de la relación del álbum impreso con la masificación de la imagen característica del siglo XIX. El álbum fotográfico impreso implica así un trabajo mecánico tecnificado que lo saca del espacio doméstico e individual para convertirlo en un producto estandarizado de fácil consumo. A diferencia del álbum para señoritas o del álbum familiar, el álbum impreso no requiere de la intervención del "lector"; aquí los contenidos ya están previamente establecidos. 


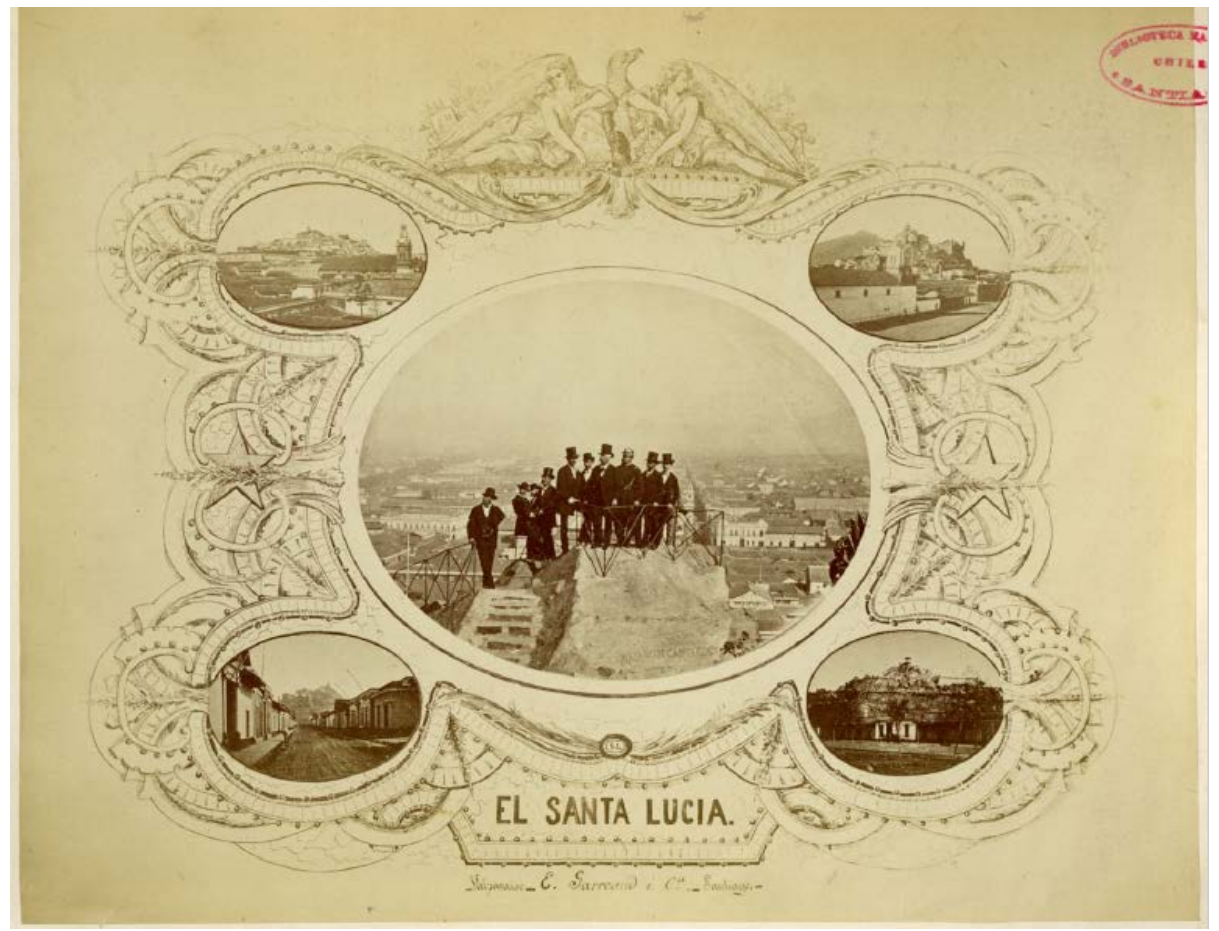

FIGURA r: Portada del Álbum del Santa Lucía (Fuente: Vicuña Mackenna, I874a. En el centro de la imagen podemos ver la fotografía de los artífices del parque y del propio Vicuña Mackenna. Las fotografías que lo rodean son tomas del parque desde la distancia)

Para 1874, año en que se publica el Álbum del Santa Lucía, los álbumes fotográficos impresos en Chile aún no tenían una gran difusión, de allí que Vicuña Mackenna más que insertarse en una tradición, ayude a construir este formato que hace de la fotografía y del texto una nueva red discursiva. ${ }^{\mathrm{I}}$ Habrá que esperar unas décadas para ver cómo se impone el álbum fotográfico impreso como una práctica regular dentro del campo editorial chileno. Ya para el entre-siglo podemos encontrar una multiplicidad de publicaciones: Salitreras de Tarapacá (i889), Álbum vistas de Valparaíso (I890), Álbum gráfico del Instituto de Higiene de Santiago (1910), Álbum gráfico militar de Chile (19го), Álbum de la zona Austral de Chile (1919), Álbum de Santiago. Vistas de Chile (1915), Chile al día. Álbum gráfico de vistas de Chile (1915-1920), Álbum de la policía de Santiago (1923), Álbum de Vistas frigorifico de Puerto Bories (1920), Álbum zona central de Chile (1923), Panorama de Chile (s/f), etc.

La variedad de títulos nos muestra no solo lo difundido que estaba ya este tipo de publicaciones en el entre-siglo, sino también las distintas funciones que estas tenían. De nuevo las agrupaciones nos permiten un cierto orden analítico. Es evidente que un grupo grande de estos álbumes fotográficos estaban ligados al Estado y a su necesidad de ordenar, clasificar, exhibir, sus

\footnotetext{
'Soledad Chávez Fajardo, en "De un jardín aéreo. Un peñón para el proyecto higienista decimonónico" (20r4), señala la obra Chile ilustrado: guía descriptiva del territorio de Chile, de las capitales de Provincia, de los puertos principales, de Recaredo Santos Tornero, como un antecedente del Álbum del Santa Lucía. Otro antecedente importante podemos verlo en Vistas de la Patagonia, del Estrecho y de la Tierra del fuego de Pedro Emilio Garreaud (i869).
} 
instituciones. Por otra parte, los álbumes fotográficos se presentaban como lugares idóneos para mostrar -y de nuevo para organizar y clasificar- la geografía nacional: álbumes de ciudades, regiones, zonas de Chile. En otros casos, los álbumes aparecían ligados a la empresa privada y a la necesidad de visibilizar sus adelantos comerciales e industriales. Por último, otra parte de ellos se constituyeron como mercancías para el consumo de un lector/espectador que parece ávido de material visual. Por supuesto, todas estas delimitaciones son muy porosas. Pensemos incluso en el álbum que nos ocupa. ¿Se trata de un álbum puramente institucional? ¿Un producto impuro y colateral de la industria cultural? ¿Una fusión de todas estas aristas?

El prólogo del Álbum del Santa Lucía nos ofrece algunas pistas. Para empezar, encontraremos que está dividido en dos partes claramente diferenciadas: una dedicada a describir el paseo y una dedicada al álbum propiamente dicho. Estas dos secciones nos hablan de una separación entre la descripción de las reformas urbanas y las del álbum como objeto; se trata de elementos vinculados, pero no idénticos. El álbum tiene unas características que le otorgan cierta independencia de aquello que supuestamente registra, se trata de una "obra" -y esto ya es un elemento definitorio importante- que tiene su propio valor, estructura y materialidad.

El álbum, tal como señala el autor, es "una obra verdaderamente de lujo". Sus dimensiones, sus fotografías muy bien cuidadas y su lujosa encuadernación en cuero lo vuelven un objeto suntuario hecho para atesorarse, para conservarse como un objeto preciado. Ahora bien, este objeto de lujo es también una "obra de propaganda" (33), como declara el mismo autor. La materialidad apunta hacia un objeto valioso mientras que el contenido parece tener funciones más pragmáticas como la divulgación de los adelantos urbanos conseguidos en la ciudad:

Contribuir a ese saludable movimiento de regeneración por el ornato y la higiene, que construye su saludable consecuencia en nuestras ciudades, es por tanto la principal y más alta intención de este libro dedicado, en el nombre y representación de la Municipalidad de Santiago, a los municipios de toda la República. (33)

La carga institucional del libro -curioso que lo denomine de esta forma- y su componente propagandístico no impide que este cabalgue sobre prácticas estéticas que lo acercan a las formas del consumo suntuoso, como también a las formas del consumo visual imperantes en el momento. Recordemos que el siglo XIX es el siglo de los divertimentos ópticos y de la eclosión de los discursos visuales, especialmente de los fotográficos. Estas formas del entretenimiento visual mercantilizado se conjugan con las aparentemente más solemnes funciones estatales y propagandísticas de un modelo de urbanidad y, en última instancia, de república. Así, podríamos

${ }^{2}$ Para todas las citas del álbum utilizaremos la edición de Planeta Sostenible (20r4). 
pensar que El Álbum del Salta Lucía es, en su propia materialidad y su forma, una suerte de encarnación de una modernización que se refleja no solo en las transformaciones urbanas sino también en lo textual, lo fotográfico, lo material, etc. Lo lujoso del álbum no contradice lo propagandístico, por el contrario, lo apuntala como una muestra de una visualidad/textualidad moderna.

\section{FOTOGRAFÍA Y TEXTUALIDAD}

Las fotografías del Álbum del Santa Lucía fueron tomadas por Pedro Emilio Garreaud y Pedro Adams. Se trata de 49 fotografías con distintas perspectivas del cerro que vienen seguidas por un texto de Vicuña Mackenna. La relación entre Vicuña Mackenna y Garreaud tenía ya larga data. El fotógrafo francés había llegado a Chile en la década del 6o y había construido una excelente reputación por sus retratos y sus tipos costumbristas. Hacia finales de esa década, Garreaud se interesó por las vistas de paisajes y de ciudades; para I869 había creado el álbum Vistas de la Patagonia, del Estrecho y de la Tierra del Fuego, una obra donde retrataba los paisajes pintorescos del sur de Chile y de sus habitantes.

Garreaud no solo era un fotógrafo reconocido y premiado al momento de unirse al proyecto del Álbum del Santa Lucía, sino que había mostrado ya un claro interés por explorar, precisamente, el mundo de los paisajes y de las vistas, un tipo de fotografía muy distinta a la del retrato de gabinete. Hernán Rodríguez Villegas nos cuenta cómo fue ese proceso:

En I872 el establecimiento de Garreaud fue premiado por los retratos, cianotipos, reproducciones en yeso, fotolitografías y fotografías de cuatro cuartos, presentados a la Exposición de Santiago, en el Mercado Central. El mismo año inició la reproducción de vistas y paisajes de Chile, preferentemente de Santiago, Valparaíso, Cauquenes y Lota, y escenas y costumbres campesinas. En mayo de ese año el gobierno acogió su proyecto de formar álbumes de vistas de Chile, mostrando los edificios, paseos y monumentos más representativos del país. Al menos publicó el álbum fotográfico impreso Vistas de Chile, Santiago, $\mathrm{N}^{\circ}$. (Rodríguez Villegas 200I: I42)

Toda esta experiencia y este interés por fotografiar la ciudad se conjugó muy bien con el deseo de Vicuña Mackenna de crear este álbum. Tanto Garraud como Vicuña Mackenna tenían un punto de partida común, la idea de describir -visual y verbalmente- los lugares más emblemáticos de la capital. Esto nos lleva a pensar en un proyecto en conjunto donde fotografía y texto tienen un peso en sí mismo. Se trata de un trabajo colaborativo aun cuando el nombre de Garraud o el de Adams -quien trabajaba para él- no aparezcan como autores en la portada. La idea del fotógrafo como autor seguía siendo problemática para ese momento y dificultaba la idea de una autoría compartida. Como bien señala Francois Brunet, la colaboración entre fotógrafos y escritores - 
especialmente científicos o exploradores- era bastante común, pero usualmente desde una relación de desigualdad en la que el fotógrafo funcionaba como un operario:

In the nineteenth century, the dominant functions of photographic publishing was documentation, whether scientific, historical, or commercial; its main operative mode was survey or the archive; and its main product was the book or album. Often large an expensive. For the same reason, these photographic books were more often than not the result of collaborations -or mere contracts- involving hired professionals photographers who, serving illustrative goals, were generally not in a position to express authorial concerns. (Brunet 2013: 49)

La idea de la fotografía como documentación -científica, histórica, comercial- parece repetirse en este álbum, al igual que la minimización autoral del fotógrafo, sin embargo, algunos matices nos permiten dar cuenta del trabajo colaborativo Garreaud-Vicuña Mackenna. Comencemos por resaltar la forma cómo dialogan el texto (Vicuña Mackenna) y la imagen (Garreaud) en esta publicación. Lo primero que notamos al abrir el álbum es que la imagen precede el texto, un detalle no menor. ${ }^{3}$ No se toman las fotografías para ilustrar el relato, sino que se escribe a posteriori para describirlas. Las imágenes, tomadas por Garreaud, establecen un andamiaje sobre el que trabajar, un andamiaje fotográfico que determina inevitablemente la escritura. El mismo Vicuña Mackenna menciona en una de las páginas del álbum la idea de que es otro el que ha armado el conjunto visual: "el fotógrafo que ha concebido y ejecutado la presente colección ha añadido el panorama de una parte de la ciudad" (48). Garreaud establece la "colección" en la que Vicuña debe insertarse como comentarista. Esto nos obliga a pensar la imagen como eje central y a un cierto desplazamiento de la escritura como comentario de la fotografía. El cambio de un régimen textual a un régimen escópico parece aquí asomarse con nitidez.

Cuando Vicuña Mackenna escribe, ya conoce de antemano la fotografía y también su disposición dentro del álbum. Hay un orden preestablecido de lo visual que le permite entrelazar las partes del álbum a través del texto. Se refiere, por ejemplo, a "la hermosa vista que representa la lámina del frente" (36), "esta perspectiva, gemela de la que precede" (38), "esta sexta perspectiva completa la precedente" (46). Como si se tratara de espacios geográficos, Vicuña Mackenna describe las imágenes que están enfrente, detrás, más adelante y las va entrelazando y estableciendo conexiones entre ellas. No se trata de una mera superposición de imágenes y vistas, sino de un relato con un orden específico.

En su deseo de ordenar el relato fotográfico/escritural y darle una forma narrativa que cuente una historia particular, Vicuña Mackenna termina reflexionando sobre lo fotográfico, sus condiciones técnicas, su vinculación con el arte, etc. Quisiera detenerme por un momento en esta

3 En la edición facsimilar de Planeta Sostenible (2014) el orden es invertido: primero aparece el texto y luego la foto. 
suerte de meta-texto reflexivo para entender cómo se arma el relato del álbum y cómo Vicuña Mackenna va develando una manera muy particular de entender este híbrido artefacto cultural.

\section{EL INTENDENTE Y EL ESPECTRO FOTOGRÁFICO}

¿Cómo se vincula Vicuña Mackenna con esas fotografías con las que intenta dialogar? ¿Se trata de registros, creaciones, documentos? ¿Se trata de una imagen técnica o de una imagen artística? ¿Es el fotógrafo su contraparte artística, su par, o un operario? Todas estas preguntas, sin duda, han acompañado a la fotografía desde sus inicios. Desde i839, año en que se presentó el invento de Daguerre ante la Academia de Ciencias de Francia, la fotografía ha oscilado entre discursos muy disímiles: por un lado, una mirada cientificista que la percibió como un invento técnico, una manera de captar la realidad; por otro lado, un discurso que la ligó a las artes y a la posibilidad de la creación, de la representación, e incluso de la imaginación y la subjetivación; y finalmente, la noción de lo fotográfico como entretenimiento, como mercancía visual.

Muy conocidos son, por ejemplo, los argumentos de Charles Baudelaire en contra de la fotografía como arte. El poeta la llamaba "la sirvienta de las artes", el "refugio de todos los pintores frustrados, mal dotados o demasiado perezosos para acabar los estudios" (1996 233). Pero no era el único y otros artistas se unieron a estas críticas. Conocidos también son los argumentos de Eugène Delacroix quien afirmaba que "Transcribir sin elegir es lo que determinará su función documental como mera reproductora de las artes" (en Pérez Gallardo 2015: 24).

Vicuña Mackenna, al enfrentarse a la fotografía no la atraviesa como un mero conducto para llegar a lo real, sino que se detiene en ella, en su materialidad. Le importan las reformas urbanas, sí, describir el paseo, pero también se interesa en la fotografía, en su propia condición. En una de las primeras imágenes del álbum, comenta:

Si se le preguntara, no diríamos a cualquier extranjero domiciliado en la capital, sino a un antiguo vecino y natural de Santiago, lo que representa la lámina que tiene a la vista, es más que probable que se creería en presencia de la copia fotográfica de esos grabados que exhuman algunas de las ciudades de la antigüedad, reconstruidas por las investigaciones arqueológicas de los sabios y el buril de los maestros. (40)

Vicuña Mackenna se detiene en la fotografía y se preocupa por lo que la lámina representa y por la posible confusión entre ella y un grabado. La confusión no tiene que ver con los referentes últimos, el Cerro Santa Lucía y una ciudad antigua reconstruida -o no solo con ellos-, sino con sus representaciones: la fotografía y el grabado. Para el autor, un observador inexperto puede confundir las imágenes y las técnicas utilizadas, precisamente porque ambas se presentan como 
"representaciones" llevadas a cabo por un mediador a través de una técnica específica ("el buril del maestro", la cámara fotográfica). Vicuña Mackenna ha asimilado una mirada moderna sobre el acto fotográfico y su manera de desestabilizar el vínculo entre representación y objeto. Tal como propone Paola Cortés-Rocca: "considerada en sus tres dimensiones -una práctica, una técnica y un modo de representación-, el dispositivo fotográfico propone un modo nuevo de pensar la relación entre el sujeto y el mundo, entre sujeto y objeto, entre la cosa y su representación" (20II: I8).

Para Vicuña Mackenna, ese quiebre entre "la cosa y la representación" ya es visible; la imagen fotográfica y el grabado no se conciben como prácticas antagónicas, es decir, por un lado, una creación artística y, por el otro, un mero registro de lo real, sino que ambos pertenecen al mundo de las imágenes creadas, intervenidas y ambas también pertenecen al mundo de la masificación y la reproductibilidad ${ }^{4}$.

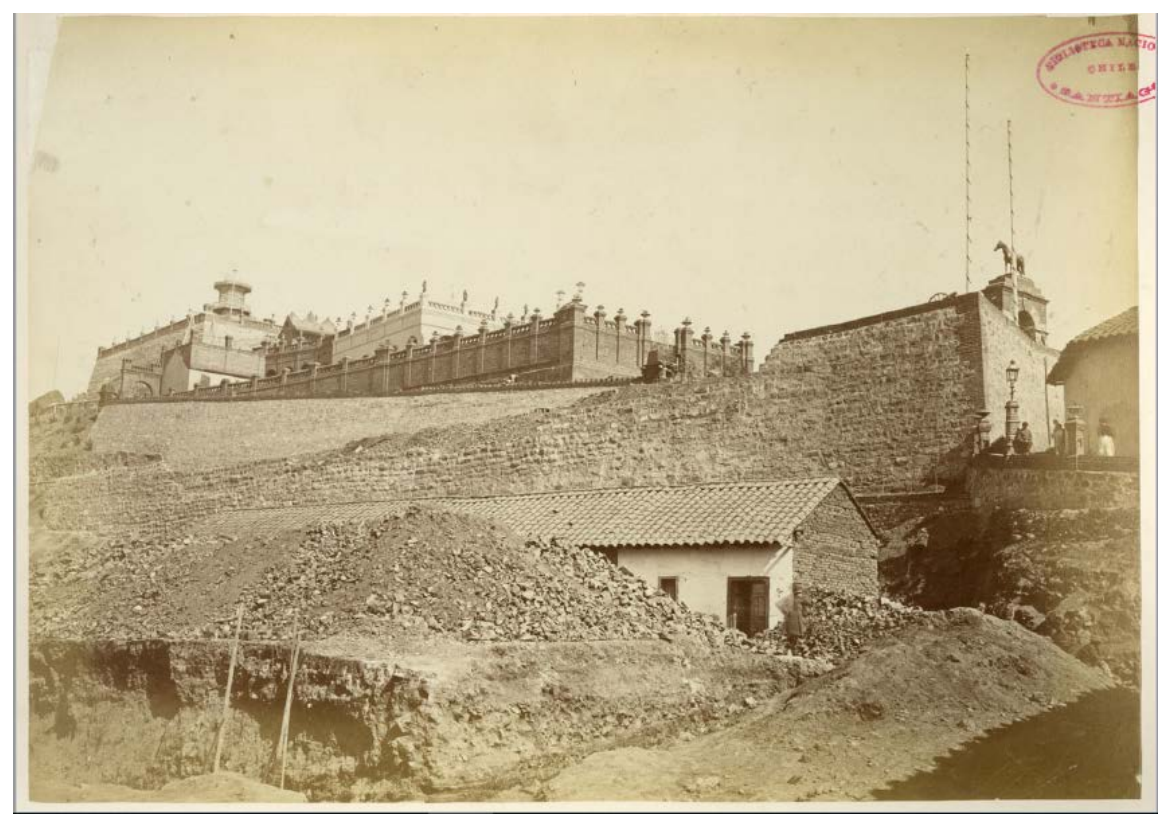

FIGURA 2. A partir de esta imagen Vicuña Mackenna discute sobre los límites borrosos entre el grabado y la fotografía (Fuente: Vicuña Mackenna, I874a.)

Si volvemos de nuevo a la cámara fotográfica y a las reflexiones de Vicuña Mackenna, veremos cómo para él este instrumento visual continuamente deja huellas y no siempre es capaz de registrar con fidelidad. Con cierta asiduidad uno puede encontrar en el texto acotaciones sobre las distorsiones que produce el aparato: "por un efecto de óptica inevitable y no siendo posible tomar la vista de esta portada sino del plano inclinado del cerro, no aparece aquella en todo su relieve ni en el nivel correspondiente" (66); "En la forma en que ha sido fotografiado, el chalet aparece un

\footnotetext{
4 Recordemos que Vicuña Mackenna hablaba ya del grabado y la litografía como medios de reproducción masificada, especialmente esta última había logrado acelerar los procesos de reproducción (2015: 27).
} 
tanto desfigurado" (68) ; "Si bien no ha sido posible a la fotografía reproducir en toda su agreste y singular belleza el anfiteatro de palmas" (II8); "Ha sido tomada esta fotografía en la fuerza del sol de primavera y por esto presentan sus masas el aspecto cálido y blanquizco" (8o). Para Vicuña Mackenna, la cámara, el aparato, a veces logra representaciones más o menos fidedignas y a veces deforma; no es un aparato de fiar precisamente porque no captura lo real, lo desfigura, lo altera. Por otro lado, el fotógrafo tampoco es un sujeto inerte, él tiene un rol muy importante en la construcción de estas representaciones.

La intervención del fotógrafo hace que las imágenes cambien y adquieran efectos más realistas o más románticos. El fotógrafo juega con la luz, los ángulos, las perspectivas, haciendo de la imagen un lugar intervenido y de alguna forma compuesto, creado. Él es, para Vicuña Mackenna, una suerte de artista que empuña una cámara en lugar de un buril. Refiriéndose a una de las primeras tomas del álbum, dice Vicuña Mackenna: "el artista ha procedido acertadamente al circunvalar el cerro con el foco de su máquina, a fin de exhibirlo en este Álbum como un verdadero diorama en una tela sin fin" (46).

La idea del fotógrafo como artista se repite a lo largo del álbum, es la forma en la que el autor se refiere al trabajo de sus colaboradores; solo en una ocasión habla del "operario" de la cámara y la referencia es un poco ambigua, no sabemos bien a quien se refiere. En cuanto a Adams, por ejemplo, no solo es nombrado como "autor" (9o) de las fotografías, sino también como hábil artista: "eligió el hábil artista señor Adams, autor de esta serie de vistas, su cúspide como el lugar más aventajado para retratar en forma de portada el estado mayor del Santa Lucía “(9o). No quiere decir esto que el "artista" renuncie a la posibilidad del "registro", sino que pareciera que este depende de la voluntad/capacidad/gusto del fotógrafo: "Entre las treinta y tantas estatuas que adornan el Santa Lucía, el artista ha querido reproducir con su máquina alguna de las más interesantes y al copiar la que representa la lámina que está a la vista no lo ha engañado ciertamente su buen gusto" (I20). Al establecer el foco en "el buen gusto", Vicuña Mackenna coloca el acento sobre el fotógrafo, su concepción artística y le resta importancia al aparato y a su capacidad de reproducir.

Imposible dejar de pensar aquí en Vilém Flusser y en su estudio sobre la imagen técnica, especialmente la fotográfica. Por un lado, la idea de que el aparato condiciona/media la imagen: "en el gesto fotográfico el aparato hace lo que el fotógrafo quiere, y el fotógrafo debe querer lo que el aparato puede" (2014: 39), y, por otra parte, en la idea de que los conceptos preceden la imagen: "Para poder ajustar el aparato para imágenes artísticas, científicas y políticas, el fotógrafo debe 
tener conceptos del arte, la ciencia y la política: de lo contrario, ¿cómo podría traducirlos a imágenes? No existe el fotógrafo ingenuo, sin concepto. La fotografía es una imagen de conceptos" (2014: 40).

Visto así, la noción de lo artístico precede y a la vez construye la imagen artística. La manera como Vicuña Mackenna entiende la fotografía viene condicionada por esas nociones que como ya vimos circulaban en el siglo XIX en donde el registro fotográfico oscilaba entre el ámbito científico, el arte y la industria del entretenimiento. Vicuña Mackenna también oscila a ratos, pero, como ya vimos, se inclina por la visión del fotógrafo-artista. Recordemos que para la fecha en que se publica el álbum la condición artística de la fotografía seguía siendo muy polémica. Incluso varias décadas después se seguía discutiendo sobre esta posibilidad. En I9oo, por ejemplo, en la revista chilena Instantánea. Semanario Festivo, Literario, Artístico y de Actualidad, el redactor hace una breve disertación sobre el valor artístico de la fotografía y su relación con el canon pictórico:

La fotografía artística, en que está unida a la bondad y perfección del trabajo mecánico del fotógrafo el talento que dispone la composición de los grupos, la línea de los paisajes, los juegos y contrastes de luz de la naturaleza, viene a suplir en las grandes revistas europeas el trabajo del dibujante y del pintor. Si al pie de esas reproducciones fotográficas no se expresa que son copias del natural, se las creería cuadros de manos maestras por la artística disposición de las figuras, el estudio concienzudo de la luz y de la sombra y la serenidad clásica de la composición. (22 de abril de 1900$)$

Tanto el redactor de la nota como Vicuña Mackenna parten de la idea de la confusión: la fotografía artística puede ser confundida con el grabado (o la pintura) porque ambas parten de los mismos cánones estéticos y principios de composición. La fotografía se legitima no por sus propios mecanismos y búsquedas estéticas, sino por su proximidad con lo pictórico. El vínculo de lo fotográfico con lo pictórico sin duda es una constante dentro de las discusiones globales sobre el hecho fotográfico, pero que recuperadas aquí nos muestran como Vicuña Mackenna está familiarizado con estas discusiones y cómo deambula sobre ellas.

Unos años más tarde, en 1909, el fotógrafo Luis Navarrete seguirá haciéndose la misma pregunta: "Tema viejo en otros países, pero nuevo en Chile, es dilucidar si la fotografía es un medio de llegar al arte, o, en otros términos, si es posible, por la representación fotográfica, interpretar la Naturaleza y llegar a hacer "obra de arte" (Navarrete: 96). Agrega Navarrete que para lograr alcanzar esa condición artística el fotógrafo debe aprender a dominar y subyugar a la máquina:

El fotógrafo debe subordinar los aparatos y toda la técnica a su voluntad: de otro modo seguirá siendo un simple operario mecánico, esclavo de una máquina y tiranizado por las exigencias de un formulario rígido... Es decir, todos los elementos de trabajo han de ser, para el fotógrafo que aspira a "hacer obra de arte", lo que para el pintor son la tela, los colores y los pinceles. (97) 
Vicuña Mackenna, así como Navarrete unas décadas después, insisten en ver el aparato fotográfico como un instrumento muy parecido a los utilizados por la pintura: el buril del que nos hablaba Vicuña Mackenna y los pinceles y los lienzos de Navarrete. La fotografía se presenta como obra de arte en la medida en que ella puede someterse a la mirada, al gusto y a la voluntad del "autor". La máquina tiene que pasar por un proceso de subjetivación artística, si no, ella es mera reproductora, puro registro y el arte, bajo esta mirada romántica, no puede ser solo eso5.

\section{ÁLBUM Y ESPECTÁCULOS}

Para complejizar un poco más la noción de Vicuña Mackenna sobre la fotografía como una posibilidad artística hay que tomar en cuenta un elemento que aparece de manera más sutil en sus reflexiones. Vicuña Mackenna no solo compara la fotografía con el grabado, sino también "con la tela de un diorama sin fin". Esta analogía introduce un tercer elemento: el de las formas modernas y masificadas del entretenimiento visual.

Tanto el diorama como el panorama marcan con nitidez el acceso del público masificado a una forma de entretenimiento escópico novedosa; una forma aparentemente más cercana al espectáculo que al arte. Para Walter Benjamin, el panorama representa justamente el instante en que la pintura se separa del arte para convertirse en otra cosa, en simulacro de lo real:

Así como la arquitectura, que en la construcción en hierro comienza a emanciparse del arte, la pintura hace otro tanto con los panoramas. El punto culminante en la difusión de los panoramas coincide con la aparición de los pasajes. Se hacían incansables esfuerzos por convertir los panoramas en lugares de una imitación perfecta de la naturaleza a través de artificios técnicos. Intentaban imitar los cambios de las horas del día, la salida de la luna, la caída del agua en las cascadas. (1981: I23)

Los panoramas parecen funcionar, así, como prácticas que se van despegando del mundo del arte para entrar en el ámbito de lo comercial y de lo espectacular. Vicuña Mackenna, al hablar del diorama, no solo ratifica una vez más las conexiones entre pintura y fotografía, sino que vincula esta última con una forma del espectáculo de masas. Recordemos que el diorama consistía en grandes lienzos pintados que eran iluminados desde distintos ángulos y que producían la ilusión de la perspectiva y a veces del movimiento. Se trataba de un espectáculo visual muy popular en el siglo XIX, aun cuando en el XVIII ya se conocía su existencia. El Intendente está familiarizado con estas formas modernas de la visualidad y de alguna forma las vincula con su proyecto. Hacia el final del

5 Para una revisión exhaustiva de este proceso en Chile ver Nicol Iroumé y Paulina González, Recorridos Fotográficos. Hacia la legitimación de la fotografía como obra de arte (2018). 
libro volvemos a encontrar este vínculo; al hablar de la vista de los Andes dice: "cuyas nevadas cimas se presentan aquí como en la tela de un diorama" (II2).

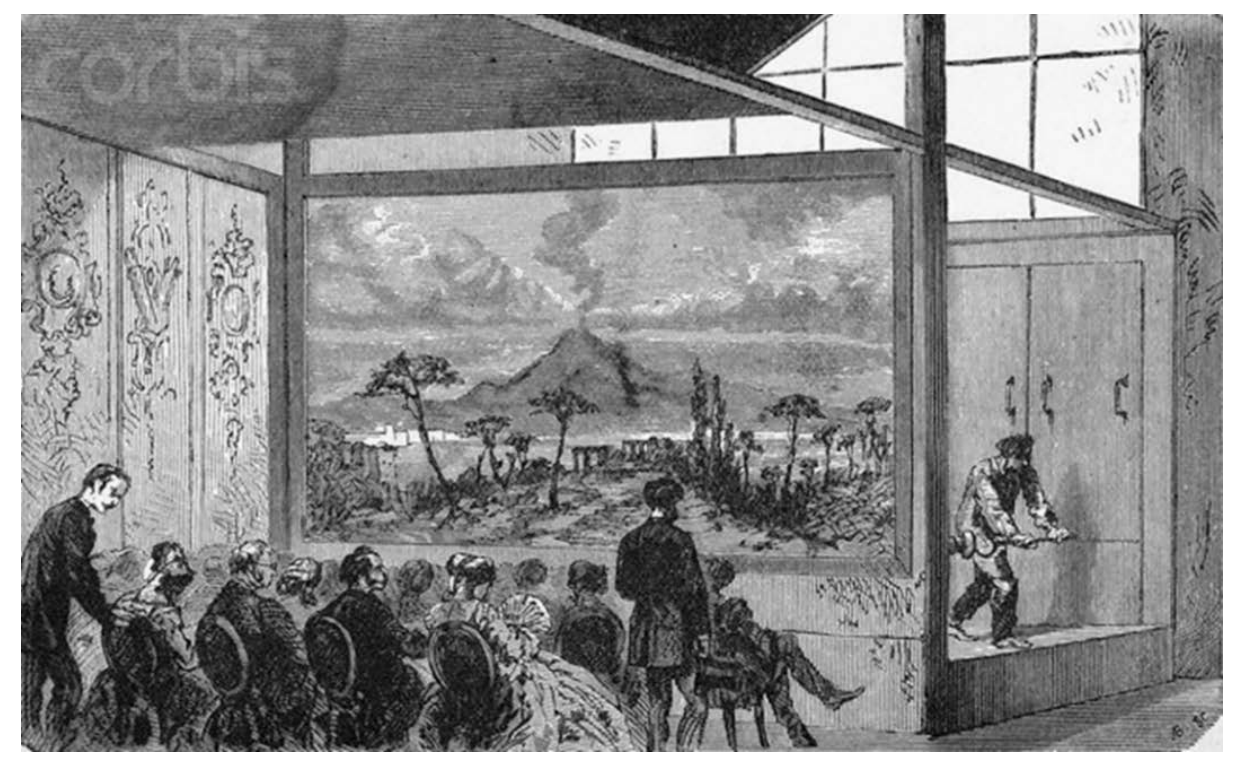

FIGURA 3. Grabado de madera del siglo XIX donde se representa el diorama como forma de entretenimiento (Fuente: Vicuña Mackenna, 1874a).

Autores como Pérez de Arce (1993) y Amari Peliowsky (2018) ven en esta referencia de Vicuña Mackenna al diorama un error de interpretación. Ambos parten de que Vicuña Mackenna confunde el diorama con el panorama, sin embargo, quisiera insistir en que Vicuña Mackenna sí conoce la diferencia entre ambos aparatos. En las dos ocasiones en que Vicuña Mackenna menciona el diorama lo hace como comentario de una fotografía y en ambas fotografías es posible ver el porqué de esta analogía. En la primera, el cerro Santa Lucía es visto desde la distancia y se encuentra enmarcado por dos hileras de casas lo que crea una suerte de marco que delimita el cerro, podríamos decir incluso que es una foto anti-panorámica. En la segunda fotografía, "El desfiladero de los Andes", sucede algo muy parecido: la cordillera se divisa al fondo enmarcada por una roca y una construcción, de nuevo se trata de una imagen cerrada, delimitada, que impide la vista panorámica. En ese sentido, ambas imágenes guardan una enorme similitud con el diorama que, a diferencia del panorama, no simula la visión de los 360 grados, sino que enmarca la imagen, la recorta como una ventana por la que asomarse ${ }^{6}$.

\footnotetext{
${ }^{6}$ Vale la pena agregar, además, que en los diarios de viaje de Vicuña Mackenna, específicamente en "Páginas de mi diario durante tres años de viaje, I853-1854-I855" este menciona dentro de los atractivos de París que no se pueden dejar de visitar, la rotunda del Panorama: "Aquí el Circo de la Emperatriz o el Hipódromo os ofrecen un mas noble i gracioso pasatiempo, o entrais a admirar la rotunda del Panorama que ha desaparecido para dar lugar al Palacio de la Industria" (I867: 134). Sabemos así por sus propios registros que Vicuña está familiarizado con este tipo de artefactos visuales y que conoció la manera cómo funcionaban. La rotunda era la base circular sobre la que se instalaba el panorama.
} 


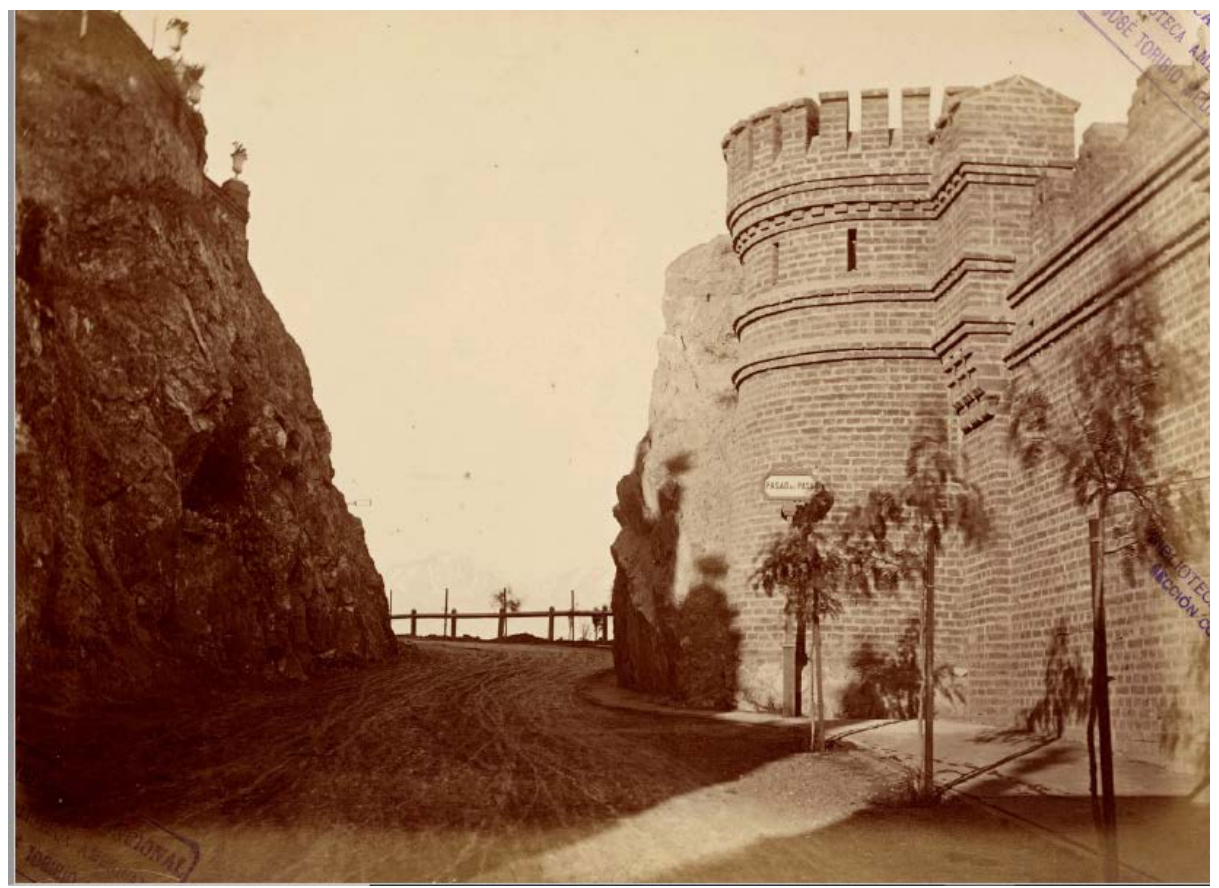

FIGURA 4. "El desfiladero de los Andes" (Fuente: Vicuña Mackenna, I874a. En la composición de esta fotografía es posible observar por qué Vicuña Mackenna insiste en comparar algunas imágenes del álbum con las formas del diorama. En esta imagen la roca de la montaña y la pared del castillo funcionan como marcos que encierran y acotan la imagen).

Podríamos decir incluso que el propio Álbum del Santa Lucía funciona como un tipo de diorama. Se trata de una suerte de aparato óptico desde el cual podemos asomarnos, como a través de una ventana, a las reformas del cerro y a las de la ciudad. Tanto las imágenes como los textos se encuentran enmarcados por unas claras líneas que los delimitan y que nos muestran fragmentos que tenemos que ir conectando. De alguna forma, Peliowsky y Valdés (2018) intuyen esta fragmentación al mencionar que:

El álbum no incluyó un panorama completo que fuera tomado, por ejemplo, desde alguno de los miradores más altos del paseo y produjera una fotografía compuesta -siguiendo el ejemplo de las fotografías secuenciales que Eugène Maunoury tomó en la década anterior o realizada con cámaras ad hoc disponibles ya para la época. Pero es en la propia experiencia panorámica, en el paseo mismo, que se logra esta vista, posibilitada por terrazas, miradores e incluso muros almenados que restituyen, varias décadas después de la construcción de las primeras baterías militares, la condición de mirilla del cerro. (246)

Si bien las autoras insisten en que la mirada panorámica se produce a posteriori, esto no deja de ser una mirada fragmentada que, en efecto, hay que reconstruir. Lo panorámico no se produce en la fotografía o en el álbum sino en el paseo mismo, en la disposición de sus terrazas y miradores. La estructura del propio álbum apunta a una serie de escenas que el espectador/paseante debe conectar a través de un guión preestablecido por el propio Vicuña Mackenna. Tanto el diorama 
como el álbum requieren de ese guión (textual/visual) que permite conectar las partes y darles sentido. Recordemos que el diorama, tal como apunta Jonathan Crary:

Se basaba en la incorporación de un observador inmóvil en un aparato mecánico y su sujeción a una experiencia óptica cuyo desarrollo temporal está prediseñado. La pintura del panorama, circular o semicircular, rompió obviamente con el punto de vista localizado de la pintura perspectiva o de la cámara oscura, permitiendo al espectador una ubicuidad móvil [...] el diorama multimedia privó al observador de esa autonomía, a menudo situando al público en una plataforma circular que se movía lentamente, y permitía vistas de diferentes escenas y efectos cambiantes de luz. (2008: 151)

La experiencia del álbum y del diorama $a^{7}$ parten de una estructura que imposibilita que el espectador deambule y se mueva libremente por el espacio y por la imagen, sino que su mirada está sujeta, precisamente, a ese prediseño. De allí que el recorrido que Vicuña Mackenna nos propone esté estructurado a través de escenas que él ha seleccionado, ordenado, iluminado, para que funcionen como una guía. De allí también que la presencia del texto escrito se vuelva vital para acompañar el recorrido visual y para ayudar a narrativizarlo. Las fotos y los textos no están puestos al azar, ellos responden a un orden bastante lineal donde lo visual se convierte en relato y en guión.

\section{EL PASEO COMO RELATO}

¿Cómo se construye un relato a partir de las fotografías y los textos que componen el álbum? ¿Cómo se articula desde el fragmento? ¿Cómo se establece la unidad del álbum?

A photo album's narrative is conveyed through design and page layout. Choices for layout, sequencing, and captioning of photographs are flexible and at the whim of the creator... The arrangement of photograph on a single page or a double-page spread allows a creator to form associations among images. Strategic juxtaposition of photograph on double-page spreads can be a way to suggest new meanings or to editorialize. The album creator can also use captions to influence the viewer, provide essential data, offers opinions. (Curtis 20II: 9)

Volvamos de nuevo a la estructura del álbum. Tal como argumenta Curtis, los álbumes fotográficos suelen construir su narrativa -en el caso de que las haya- a través de la disposición de las fotografías, las secuencias, las yuxtaposiciones, los textos que las acompañan. En el caso del Álbum del Santa Lucía, la estructura es bastante simple: en la página izquierda encontramos una fotografía que ocupa todo el espacio y en la página derecha aparece el texto -este varía en longitud, pero nunca excede la página-. El texto aparece numerado y enmarcado por unas líneas con un detalle decorativo en las esquinas y una viñeta en la parte inferior.

\footnotetext{
${ }^{7}$ La relación entre la hibridez medial del diorama y cierto tipo de libros y publicaciones en el siglo XIX ha sido analizada en trabajos como los de Kirstyn Jean Leuner en su texto The Diorama and the Book in the Romantic Era and Nineteenth Century (1780-1860): "Still Craving Combinations of New Forms" (2014).
} 
Dentro de este orden estructurado nos damos cuenta de que hay una secuencia -tanto en las imágenes como en los textos- que implica una aproximación gradual al parque. En las primeras seis fotografías vemos al Cerro Santa Lucía desde la distancia, el encuadre se produce desde la ciudad; a veces las fotografías están tomadas desde un punto de vista elevado, en otras el fotógrafo toma el cerro desde el suelo. Cada una de las fotos y los textos nos aproximan un poco más al cerro.

Estos textos/fotografías nos van indicando las direcciones que debemos tomar. Una vez que hemos llegado al parque se nos muestra la entrada, sus límites enrejados. Vicuña Mackenna denomina a esta fotografía "La portada". Se trata del pórtico del parque, pero también de su portada porque el parque se presenta también para ser leído y contemplado. Después de la "portada" vemos cómo las fotos van siguiendo un recorrido preestablecido transformando al fotógrafo, al escritor y al lector/espectador en paseantes. Vamos tomando los caminos del parque y nos detenemos cada tanto para contemplar. En esas paradas en el camino se nos invita a observar algunos detalles como: "La estatua de Caracas", "La gruta de Neptuno", "El balcón de Ustáriz", "Las Diosas", "El cupido de Boucardon", "La Ermita", etc. El fotógrafo pasa de las panorámicas a los primeros planos guiando, junto a las palabras de Vicuña Mackenna, todo el proceso de contemplación del álbum/parque. Las fotografías oscilan con frecuencia entre el picado y el contrapicado. De esta manera, el fotógrafo, al colocarse en el lugar del paseante, le muestra formas de mirar hacia arriba y hacia abajo. Hay toda una pedagogía de la mirada que indica cómo se contempla cuando se pasea, o cómo debería hacerse. El paseante es llevado de la mano por una ruta preestablecida donde se le enseña a pasear y a mirar.

Así, Vicuña Mackenna va conduciendo al lector paseante, no le permite deambular, ni salirse del guión: "vamos por consiguiente a conducir al público en una rápida excursión por los mil senderos, escalas, desfiladeros, mesetas, jardines, bosquecillos y edificios del Santa Lucía" (Vicuña Mackenna: 2I). Se trata de un viaje circular, cerrado, que le otorga unidad a ese espacio que está contenido detrás del pórtico, pero también al álbum. El álbum debe ser leído secuencialmente para que tenga sentido. En ambos casos, el paseo se convierte en un elemento que narrativiza e integra las escenas.

El paseo como elemento aglutinante y ordenador ya había sido observado por Julio Ramos en los cronistas latinoamericanos del siglo XIX: "El paseo ordena, para el sujeto, el caos de la ciudad, estableciendo articulaciones, junturas, puentes, entre espacios (y acontecimientos) 
desarticulados. De ahí que podamos leer la retórica del paseo como una puesta en escena del principio de narratividad en la crónica" (2009: 232). ${ }^{8}$

De esta manera, el paseo crea una linealidad narrativa a partir de elementos aparentemente inconexos. El álbum no reúne fotos al azar, sino que establece un recorrido narrativo/visual que tiene un principio, un desarrollo y un final. A diferencia de muchos otros álbumes donde las colecciones fotográficas tienen una estructura significante más cercana al montaje, el Álbum del Santa Lucía intenta una linealidad narrativa que viene dada, precisamente, por una cartografía previa. Tal como ya mencionábamos, las imágenes y los textos tienen una secuencia marcada por el recorrido desde las afueras del parque hasta su estación final.

Esta narrativización del álbum nos muestra una forma de contar, ordenar y estructurar que se separa de formas más tradicionales como las del libro y la cultura escrita. Por un lado, intenta hilar desde lo fragmentario y aparentemente desconexo un relato unificador y, por otro, integra distintos lenguajes y materialidades. La fotografia y el texto logran intrincarse sin someterse uno al otro. Se trata de la creación de un tercer espacio donde esas materialidades se funden en una nueva red discursiva.

Vicuña Mackenna logra construir un artefacto visual moderno perfectamente acorde con su igualmente moderno parque urbano. Las conexiones que establece entre el relato, la fotografía, el texto, el diorama, la representación, el paseo, nos muestran una familiaridad con un régimen escópico que cada vez irá tomando más fuerza y que establecerá nuevas formas de significar. Sus continuas reflexiones sobre la fotografía, su estatuto, su forma de funcionar y de intervenir lo que toca. Sus igualmente pertinentes discusiones sobre las formas ópticas de entretenimiento nos muestran una conciencia de una visualidad moderna que articula nuevos relatos y nuevas formas de construirlos.

De allí que El Álbum del Santa Lucía no debería verse solo como un mero registro sino como un artefacto cultural que entrelaza distintas maneras de concebir lo visual y lo verbal. De allí también que resulte necesario develar los diálogos que se establecen entre este artefacto y un horizonte de lectura/consumo marcado tanto por la presencia de otros álbumes y otros aparatos ópticos, como también por otras formas como los impresos ilustrados, las revistas, la prensa, los

\footnotetext{
${ }^{8}$ Esta retórica del paseo como hilo conductor podemos observarla también en la Guía popular y breve descripción del paseo para las personas que lo visiten (i874) publicada por Vicuña Mackenna ese mismo año. Tanto en el álbum como en la Guía, Vicuña Mackenna utiliza el mismo texto introductorio y establece así el mismo recorrido preestablecido, solo que en la Guía popular la articulación es puramente textual ya que no cuenta con las fotografías.
} 
afiches, los magazines, la publicidad, etc. El universo impreso del entre-siglo trae nuevos formatos y nuevos diálogos verbales/visuales; se trata de un universo heterogéneo, múltiple, cambiante que nos sumerge en un escenario con "unos códigos y unas sensibilidades que traen inéditas improntas culturales" (Ossandon 2005: 9). Se trata de formas muy novedosas de entender la cultura, el arte, la contemplación, la lectura y el consumo y que el Intendente parece manejar con comodidad más allá de su tradicional condición letrada.

\section{REFERENCIAS}

Baudelaire, Charles. Salones y otros escritos sobre arte. Madrid: Antonio Machado, 1996.

Benjamin, Walter. Estética de la imagen. Buenos Aires: Biblioteca de la mirada, 2015.

Benjamin, Walter. El París de Baudelaire. Buenos Aires: Eterna Cadencia, 2012.

Benjamin, Walter. Libro de los pasajes. Madrid: Ediciones Akal, I98I.

Brunet, Francois. Photography and Literature. Londres: Reaktions Book, 2013.

Chávez Fajardo, Soledad. "De resemantizaciones, remedos y reminiscencias. El Cerro Santa Lucía y su intervención". Arteologie, nº 3, 2012.

Chávez Fajardo, Soledad. "De un jardín aéreo". Álbum del Santa Lucía. Santiago de Chile: Planeta sustentable, 2014.

Cortez-Rocca, Paola. El tiempo de la máquina. Retratos, paisajes y otras imágenes de la nación. Buenos Aires: Colihue, 20II.

Crary, Jonathan. Las técnicas del observador. Visión y modernidad en el siglo XIX. Murcia: CENDEAC, 2008.

Flusser, Vilém. Para una filosofía de la fotografía. Buenos Aires: La marca editora, 2014.

Hidalgo, Germán. "Panoramic view and national identity. Two of Santiago de Chile's public spaces in the second half of the nineteenth century", Planning perspectives, vol. $24, \mathrm{n}^{\mathrm{o}}{ }_{3}, 2009$.

Iroumé, Nicol y Paulina González. Recorridos Fotográficos. Hacia la legitimación de la fotografía como obra de arte. Santiago de Chile: Ministerios de la Cultura, las Artes y el Patrimonio, 2018.

Leuner, Kirstyn Jean. The Diorama and the Book in the Romantic Era and Nineteenth Century (1780-1860): "Still Craving Combinations of New Forms". University of Colorado Boulder: English Graduate Theses \& Dissertations, 2014.

Navarrete, Luis. "La fotografía artística". Selecta. Revista Mensual, Literaria y Artística, Año I, nº 3, I909. 
Ossandón, Carlos y Eduardo Santa Cruz. El estallido de las formas. Santiago de Chile: LOM/Universidad ARCIS, 2005 .

Pérez de Arce, Rodrigo; Astaburuaga, Ricardo; Rodríguez, Hernán. La montaña mágica: el cerro Santa Lucía y la ciudad de Santiago. Santiago de Chile: ARQ, 1993.

Peliowski, Amari. 2016. "L'album du Santa Lucía. Photographier la perspective urbaine". En Hélène Bocard y Jean-Philippe Garric. Architectes et photographes au XIXe siècle. Paris: Publications de l'Institut national d'histoire de l'art, 2016.

Peliowski Dobbs, Amari y Catalina Valdés Echenique. "Santa Lucía. Imágenes de un cerro que mira una ciudad”. Urbana: Rev. Eletrónica Cent. Interdiscip. Estud. Cid, vol. Io, nº I, 2018.

Posever Curtis, Verna. Photographic Memory. The Album in the age of Photography. New York: Apertire Foundation, 20II.

Ramos, Julio. Desencuentros de la modernidad en América Latina. Caracas: El perro y la rana, 2009.

Robinson, H. P. Picture making by photography. London: Scovill Manufacturing Company, I884.

Rodríguez Lehmann, Cecilia. "La fotografía y el álbum de cigarrillos. Relatos menores del entresiglo venezolano" Estudios Filológicos, n 61, 2018.

Rodríguez Villegas, Hernán. Fotógrafos en Chile durante el siglo XIX. Santiago de Chile: Centro Nacional del Patrimonio Fotográfico, 200I.

Vicuña Mackenna, Benjamín. Álbum del Santa Lucía. Santiago de Chile: Planeta Sostenible Ediciones, 20I4.

Vicuña Mackenna, Benjamín. Álbum del Santa Lucía. Santiago de Chile: Imprenta de la Librería del Mercurio, I874a.

Vicuña Mackenna, Benjamín. Guía popular y breve descripción del paseo para las personas que lo visiten. Santiago de Chile: Imprenta de la Librería del Mercurio, I874b.

Vicuña Mackenna, Benjamín. Páginas de mi diario durante tres años de viaje, i853-I854-I855. Santiago de Chile: Imprenta del ferrocarril, I856. 